\title{
Projeto Vila Ribeirinha: conjunto habitacional para área de ressaca em Macapá (AP)
}

\author{
Ivan Manoel Rezende do Valle ${ }^{1}$, Natália Yolanda Moraes Alves ${ }^{2}$ e \\ Jodival Mauricio da Costa ${ }^{3}$
}

\footnotetext{
1 Doutor. Professor da Faculdade de Arquitetura e Urbanismo da Universidade de Brasília, Brasil. E-mail: vallefau@unb.br 2 Arquiteta e Urbanista pela Universidade Federal do Amapá, Brasil. E-mail: natiyolanda@hotmail.com

3 Doutor. Professor do Curso de Arquitetura e Urbanismo da Universidade Federal do Amapá, Brasil. E-mail: jodival.costa@unifap.br
}

RESUM 0: 0 estudo explora os estigmas criados acerca da ocupação habitacional nas áreas de ressaca na cidade de Macapá (AP), utilizando como uma das ferramentas metodológicas a desconstrução do processo de ocupação, elencando assim: os fatores que colaboram com esse processo, o papel da legislação e a ótica dos habitantes locais. Por meio destas variáveis o objetivo do trabalho será propor a possibilidade e viabilidade da vivência em áreas de ressaca sem promover ou incentivar a degradação desses ambientes, entendendo a própria cultura amazônica de habitar sobre as águas como elemento de conservação da natureza. Para as conclusões obtidas acerca do tema foram utilizados referenciais teóricos e projetuais, e por fim os resultados obtidos através da aplicação de questionários in loco, possibilitando assim o entendimento da percepção dos moradores, a identificação da clientela e suas necessidades, o que será aplicado na produção de um projeto que se adeque à área e contribua com a vivência cotidiana populacional, gerando assim uma possível solução para um problema que perdura há anos sem resposta.

Palavras-chave: área de ressaca, palafitas, aglomerados subnormais, ocupação habitacional.

\section{Riverside village project : housing set to surf area Macapá (AP)}

\begin{abstract}
: the study explores the stigmas created about housing occupation in the areas of surf in the city of Macapá (AP), using as one of the methodological tools to deconstruct the occupation process, so listing: the factors that contribute to this process, the role of legislation and the perspective of the locals. Through these variables the main goal is to propose the possibility and feasibility of experience in surf areas without promote or encourage the degradation of these environments, understanding the very Amazonian culture of living on the water as nature conservation element. For conclusions on the subject were used theoretical and projective references, and finally the results obtained by applying on-site questionnaires, thus enabling the understanding of the perception of residents of customer identification and their needs, which will be applied in production of a project that fits the area and contribute to the population daily life , thus generating a possible solution to a problem that has lasted for years unanswered.
\end{abstract}

Keywords: surf área, stilts, subnormal agglomerates, housing occupation. 


\section{INTRODUÇÃO}

Hoje a sociedade brasileira vive em um cenário onde o crescimento populacional se destaca juntamente com a demanda por necessidades primárias como ensino, saúde e moradia. Atender as necessidades populacionais é uma tarefa árdua, principalmente no caso da moradia, pois como consequência do aumento populacional está o crescimento da demanda por espaço útil para ocupação habitacional.

De 1950 a 2013 a população mundial praticamente triplicou e esse processo contínuo de crescimento constitui hoje um dos maiores temores para a sociedade e para os cientistas, pois a gestão e planejamento das cidades ainda não consegue controlar os recursos e a estrutura existente diante do ritmo do crescimento populacional. Essas problemáticas encontram respostas principalmente no planejamento adequado das cidades, no modo como estas são concebidas ou reorganizadas.

Considerando que o Brasil ocupa hoje a quinta posição no ranking dos países mais populosos, é necessário refletir sobre como tem se manifestado a ocupação desse contingente populacional e quais medidas estão sendo adotadas nesse contexto. Diante de fatores como: a ausência de lotes habitáveis (localizados em terra firme e com acesso a infraestrutura) acessíveis a renda da maioria, a proximidade de serviços (ensino, saúde e comércio), e a especulação imobiliária, muitas famílias brasileiras optam pela ocupação em locais mais acessíveis a condição financeira que possuem, estes são critérios que delimitam a escolha do lote, que na maioria dos casos está instalado em áreas classificadas como aglomerados subnormais ${ }^{1}$.

Diante das problemáticas elencadas, a temática desenvolvida no estudo é a ocupação em áreas irregulares, o que constitui uma realidade crescente no país e atinge inclusive áreas protegidas pela legislação ambiental. Considerando essa abordagem foi escolhida a cidade de Macapá (AP) para o desenvolvimento do estudo, com atenção especifica para a ocupação residencial em locais conhecidos como "Áreas de Ressaca". Segundo Neri $(2004$, p. 3) Ressaca pode ser definida como:

[...] uma expressão regional empregada para designar um ecossistema típico da zona costeira do Amapá. São áreas encaixadas em terrenos quaternários que se comportam como reservatórios naturais de água, caracterizando-se como um ecossistema complexo e distinto, sofrendo efeitos da ação das marés, por meio de uma intrincada rede de canais e igarapés e do ciclo sazonal das chuvas.

\footnotetext{
${ }^{1}$ Conceito criado pelo IBGE em 1987 para definir um conjunto constituído por 51 ou mais unidades habitacionais caracterizadas por: ausência de título de propriedade e por irregularidade das vias de circulação e do tamanho e forma dos lotes e/ ou carência de serviços públicos essenciais (como coleta de lixo, rede de esgoto, rede de água, energia elétrica e iluminação pública). A nomenclatura engloba os diversos tipos de assentamentos irregulares existentes no País, como favelas, invasões, grotas, baixadas, comunidades, vilas, ressacas, mocambos, palafitas, entre outros.
} 
Os objetivos do estudo se dividem em duas categorias: específicos e gerais. Os objetivos específicos visam: analisar o processo de ocupação das áreas de ressaca, seu histórico e a legislação existente; identificar as políticas públicas existentes no local, as características físicas da área de estudo, as problemáticas existentes e as necessidades da clientela. Já o objetivo geral busca como produto final a produção de uma proposta de urbanização para a requalificação da área de estudo e projetos de arquitetura para as habitações e acessos locais.

A premissa do estudo é compreender o processo de ocupação das áreas de ressaca, confrontando-Ihe com a aplicação de políticas públicas e ainda com a legislação ambiental, federal e estadual. 0 desenvolvimento do trabalho tem como intuito chamar a atenção para a necessidade de viabilizar projetos de arquitetura e urbanização para essas áreas e nessa tarefa, como metodologia de pesquisa, foi empregado o método empírico, com a aplicação de questionários socioeconômicos e visitas in loco.

\section{CARACTERIZAÇÃO DA ÁREA DE ESTUDO}

Macapá além de ser capital do estado do Amapá, possui a maior concentração populacional e também de atividades comerciais exercidas localmente. 0 estado localiza-se na região norte do Brasil e possui fronteiras com o estado do Pará, com os países Suriname e Guiana Francesa, e com o Oceano Atlântico.

A capital possui população estimada em 456.171 mil habitantes (IBGE, 2015), clima equatorial quente-úmido e vegetação abundante conservada. A cidade é de origem portuguesa e abriga marcos históricos importantes como: o M onumento da Linha do Equador que divide o estado em dois hemisférios; a Fortaleza de São José, antiga fortificação de origem militar portuguesa; a Pedra do Guindaste que abriga uma escultura do português Antônio Ferreira da Costa; e a Igreja de São José fundada em 1761. Além das construções importantes Macapá se destaca por preservar a ligação que tem com as águas, devido a origem ribeirinha local, o que se comprova com a presença de uma complexa teia de canais e lagos existente no perímetro urbano.

A área escolhida para o estudo retrata apenas uma pequena parcela da ocupação existente em áreas alagadas na cidade. 0 local pode ser definido como um assentamento subnormal sujeito a alagamento constante, devido às chuvas e a influência dos canais, atualmente faz parte da Ressaca do Congós, que é definida como uma APP Urbana (Área de Proteção Permanente Urbana).

Apesar de áreas ambientais como essa serem locais que devem ser preservados, 0 que ocorreu neste caso particular foi a desterritorialização por parte do estado com a população que se implantou nessas áreas, já que até 1999 o poder público não havia criado impedimentos para os moradores das ressacas, muitos de origem ribeirinha, se instalarem no local. Diante da postura governamental a habitação em áreas de ressaca já é uma realidade consolidada na cidade e gera transtornos para a popula- 
ção e entidades públicas, pois não existe um consenso sobre a temática e o cenário que permanece é de conformação com as habitações implantadas e proteção das ressacas não habitadas.

Ao longo dos anos foram detectadas pequenas iniciativas do poder público com relação às habitações, muitas no sentido de orientar a ocupação/moradia para que cause menos impactos ao meio ambiente, mas ainda assim permanece a necessidade de elaborar um projeto com base em pesquisas e normas que viabilizem uma solução para a habitação em áreas alagadas, visto que a proposta local não produz soluções para o problema.

É necessário ressaltar que o processo de ocupação das ressacas é reflexo do processo de especulação imobiliária, da migração e também do modo de vida desenvolvido pelos habitantes da Amazônia. Partindo então da concepção de vivência e cultura o projeto intitulado "Vila Ribeirinha" é uma proposta para a habitação nas áreas alagadas da cidade de Macapá. A proposta projetual do estudo não incentiva a instalação em APP's (Áreas de Proteção Permanente), mas sim a adequação das habitações e sistemas básicos nos assentamentos onde a moradia já existe.

\section{CARACTERIZAÇÃO DAS RESSACAS E DO PROCESSO DE OCUPAÇÃO}

Segundo Alvarez e Bahamón (2009, p. 7), historicamente o processo de habitar sobre as águas se origina no século 3.000 a.C., onde foram detectados os primeiros vestígios de construções palafíticas utilizadas por povos antigos que buscavam abrigo e proteção nas águas. Existem manifestações semelhantes principalmente na América do Sul, África e Oceania, os povos antigos dessas localidades tinham uma conexão grande com a água, viam nela a fonte de alimento, transporte, comércio e abrigo diário.

Na obra "Palafitos" (ALVAREZ; BAHAM ÓN. 2009) os autores ressaltam que a origem das construções palafíticas é reflexo de condições ambientais e econômicas de um povo e não de uma cultura ou ritual específicos, assim cada comunidade que vive sobre palafitas adapta a moradia em função do ambiente que vive. Apesar das adaptações que o sistema de palafitas sofre em cada região, ele se destaca por ser secularmente empregado pelas pessoas que buscam abrigo sobre as águas e por atualmente ter sofrido poucas mudanças em seu método construtivo e ainda nos materiais empregados na construção.

Apesar de não ser recente a ocupação de áreas alagadas ainda gera conflitos e levanta muitos questionamentos, principalmente quanto a questão de ocupar ou não estas áreas. Não foi previsto o planejamento urbanístico e sanitário para as áreas de ressaca visto que a postura exigida era de preservação desses locais, o que inicialmente foi previsto de forma indireta na legislação ambiental e somente a partir da década de 90 passa a ser direcionado de modo específico para essas áreas. 
O que se tem em contrapartida a preservação é o fato de que essas áreas não são utilizadas para outros fins, como o turismo ou educação ambiental, não existe um trabalho efetivo de divulgação de informações sobre esse ambiente. Esses fatores apenas contribuem com a estigmatização das áreas, que acabam sendo ocupadas ou se transformando em depósitos de lixo residencial.

Em Macapá a habitação sobre as aguas existe há mais de 50 anos e se manifesta principalmente na forma de residências sobre palafitas situadas nas margens dos canais, lagos e igarapés existentes na malha urbana da cidade. As áreas ocupadas são denominadas popularmente como "ressacas", são áreas que atuam como depósitos das planícies fluviais antigas e servem principalmente para a drenagem natural das águas pluviais e das marés.

De acordo com Portilho $(2010$, p. 3) o processo de ocupação das ressacas em M acapá teve início em 1950 e foi acelerado principalmente devido aos investimentos da mineradora ICOM I (Indústria e Comércio de M inérios), pela transformação do território em estado e pela criação da Área de Livre Comércio na capital e em Santana, cidade vizinha. Esse conjunto de fatores indutores tornaram a cidade alvo do processo de migração, que foi responsável por induzir a instalação da nova população nos assentamentos mais acessíveis, nesse caso as áreas de ressaca. Na época a ocupação desses locais podia ser bem vantajosa, pois nessas não havia a cobrança de impostos e nem a venda de lotes, e a proximidade com o centro da cidade facilitava 0 acesso as atividades comerciais.

Em Macapá e Santana a presença das ressacas é bem expressiva, totaliza 27 unidades nas duas cidades, com maior ocorrência em Macapá onde estão vinte e três dessas áreas. São elas: Chico Dias, Lagoa dos Índios, Açaí, Beirol, Canal do Jandiá, Coração, Sá Comprido, Perpetuo Socorro, Congós, Lago da Vaca, Nova Esperança, Lago, Infraero II, Igarapé Davi, Igarapé do Arco, Igarapé da Fortaleza, Igarapé das M uIheres, Pacoval, Poço do Mato, Ramal 9, Lago da Vaca, Tacacá e Marabaixo, todas destacadas no mapeamento da figura 1. 
Figura 1 - Mapeamento das ressacas em M acapá e Santana.

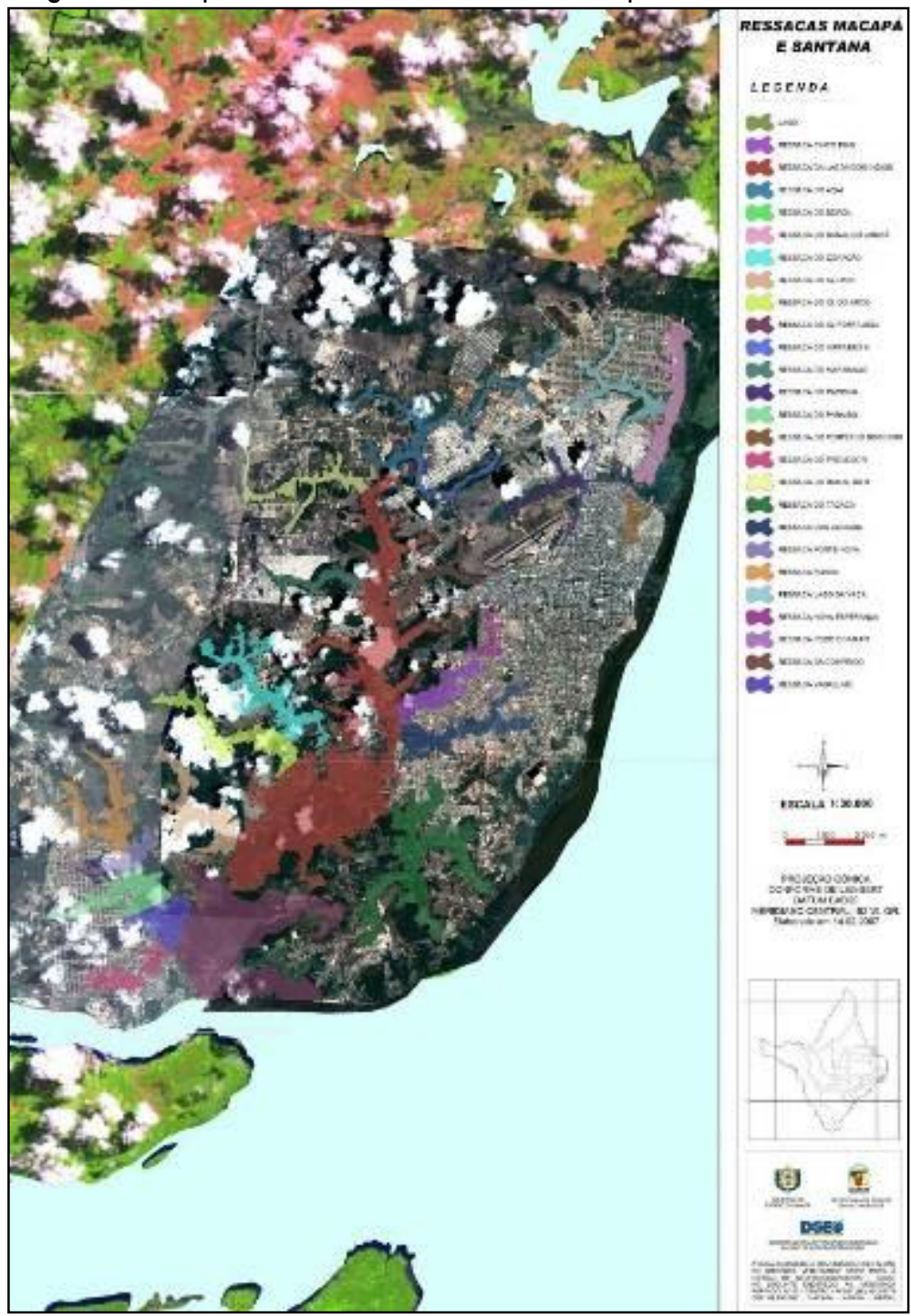

Fonte: Arquivo da SEM A/AP (2007).

A questão problemática não é habitar, mas sim a forma como ocorre a ocupação, que na maioria dos casos causa danos ao meio ambiente. A própria cidade de Macapá não é contemplada ao longo de toda a malha urbana pelos sistemas de esgotamento sanitário, o que demonstra que a poluição ou degradação gerada devido a ausência deste não é uma característica exclusiva das ressacas e de seus habitantes. Os habitantes por não terem maiores alternativas sucumbem às ações disponíveis, 0 que acarreta no depósito direto de dejetos e lixo na água, consequentemente gerando a poluição do ambiente e a diminuição da qualidade de vida obtida nas áreas.

De acordo com o IEPA (Instituto de Pesquisas Cientificas e Tecnológicas do Estado do Amapá) a preocupação com a ocupação das áreas de ressaca ocorre devido ao receio de que a degradação do ambiente ocasione sua completa descaracterização. Dentre os fatores que podem contribuir para a descaracterização das ressacas estão: 0 aterramento das áreas e constante despejo de dejetos e lixo, não sendo expressa- 
mente a habitação a causa dos problemas detectados. É diante dessa ótica que acredita-se que uma maneira viável de reverter esse quadro seria controlar a ocupação nas áreas e proporcionar infraestrutura necessária aos locais onde a ocupação é intensa.

\section{POĹTICAS AMBIENTAIS}

De acordo com os estudos desenvolvidos atualmente $90 \%$ das áreas de ressaca existentes em Macapá possuem algum tipo de ocupação habitacional, uma realidade que é reflexo também do descaso do poder público local. Por anos os órgãos responsáveis pela manutenção e proteção dessas áreas se mostraram omissos ao caso da ocupação, não se manifestavam para conter o avanço sobre essas áreas que inclusive são protegidas por leis estaduais e municipais. A própria legislação abre precedentes para as duas situações, de habitar e preservar, tenta assegurar a existência do ambiente natural à medida em que busca a qualidade de vida dos cidadãos. Quanto à postura das políticas ambientais, serão consideradas para avaliação as leis que amparam o ecossistema e em contrapartida o cidadão. Assim estão as seguintes legislações que asseguram a proteção do ambiente das ressacas:

A legislação ambiental que envolve esse ecossistema e o coloca na categoria de Área de Proteção Permanente, o que de acordo com o Código Florestal, Lei no12.651/12, Art. 3을 se define como:

II - Área de Preservação Permanente - APP: área protegida, coberta ou não por vegetação nativa, com a função ambiental de preservar os recursos hídricos, a paisagem, a estabilidade geológica e a biodiversidade, facilitar 0 fluxo gênico de fauna e flora, proteger o solo e assegurar o bem-estar das populações humanas.

A legislação definida através da Carta Magna do Brasil que assegura as competências dos Estados e Municípios, delegando a eles, no Art. 23, as funções de:

VI - Proteger o meio ambiente e combater a poluição em qualquer uma de suas formas.

VII - Preservar as florestas, a fauna e a flora.

A Constituição do Estado do Amapá (1991) pode ser também utilizada como referência, pois define a proteção das espécies e dos cursos d'água locais, assegurando no Art. 313, que é dever do estado:

Seção XI - preservar os ecossistemas essenciais e promover o manejo ecológico de espécies. 
Seção XII - Zelar pelas áreas de preservação dos corpos aquáticos, principalmente, as nascentes, inclusive os "olhos d'água", cuja ocupação só se fará na forma da lei, mediante estudos de impactos ambientais.

Por fim está também a Lei Estadual no 455/99 que delimita proteção direta as áreas de ressaca, proibindo:

A implantação e funcionamento de estabelecimentos potencialmente poluidores;

Obras de terraplanagem, aterramento, loteamento e abertura de canais;

Utilização como depósito de lixo;

Uso de biocidas e pesticidas sem controle;

Qualquer atividade que ameace extinguir as espécies da fauna e flora regionais.

Em contrapartida estão as legislações que asseguram a qualidade de vida à população e que afirmam ainda o papel do estado e do município como agente maior que tem o papel de proteger, orientar e coordenar a instalação da população nas áreas existentes da cidade. Dessas legislações podem ser citadas:

A lei $n-6.938 / 81$ da Política Nacional do Meio Ambiente, Art. 4ํㅜ, que assegura 0 papel do poder público de encaminhar:

I - à compatibilização do desenvolvimento econômico-social com a preservação da qualidade do meio ambiente e do equilíbrio ecológico;

III - estabelecimento de critérios e padrões de qualidade ambiental e de normas relativas ao uso e manejo de recursos ambientais;

$\mathrm{VI}$ - à preservação e restauração dos recursos ambientais com vistas à sua utilização racional e disponibilidade permanente, concorrendo para a manutenção do equilíbrio ecológico propício à vida.

O Art.30 da Carta Magna, que delega aos municípios a função de:

VIII - Promover no que couber, adequado ordenamento territorial, mediante planejamento e controle do uso, do parcelamento e da ocupação do solo urbano.

O Art.225 da Constituição do Estado do Amapá (1991) que exalta que:

Todos têm direito ao meio ambiente ecologicamente equilibrado, bem do uso comum do povo e essencial à sadia qualidade de vida, impondo-se ao poder público e a coletividade o dever de defendê-lo e preservá-lo para as presentes e futuras gerações. 
E ainda a legislação do CONAMA (Conselho Nacional do Meio Ambiente), que assegura também a proteção das áreas e as caracteriza como APP's Urbanas e destaca de acordo com Sales e Santos $(2012$, p.6) que:

Por outro lado, a Resolução no 369 do CONAMA, de 28 de março de 2006, prescreve sobre os casos excepcionais, de utilidade pública, interesse social ou baixo impacto ambiental, que possibilitam a intervenção ou supressão de vegetação em APP.

Diante das duas posturas colocadas fica explícito o papel do poder público de monitoramento e controle dessas áreas, e ainda as possibilidades de intervenção diante da realidade e cultura existentes localmente. Hoje a realidade consolidada se firma cada vez mais em cima do descaso existente, seja com o meio ambiente como também com os habitantes da cidade. À medida em que se faz uma análise direta das legislações que abrangem essas áreas é perceptível que o intuito não é evitar o contato humano com o meio, mas sim assegurar a sobrevivência do ambiente das ressacas como áreas que atuam como referência da essência fluvial do estado.

Então, na situação atual das ressacas em Macapá a elaboração de um projeto pautado na ocupação sustentável e adequada tende a ser uma medida satisfatória para adaptar o meio que já existe, ocasionando assim menos transtornos para a população, para o poder público e principalmente para o ecossistema das ressacas.

\section{POLITICAS HABITACIONAIS}

No que se refere às políticas públicas habitacionais adotadas na cidade se destaca principalmente o emprego do programa Minha Casa Minha Vida. Como Macapá apresenta grande concentração de áreas irregulares, principalmente sujeitas a alagamentos, é comum que a política habitacional empregada seja utilizada para a relocação de pessoas oriundas dessas áreas para locais em terra firme e regularizados.

A ideia de relocar esse contingente populacional para conjuntos habitacionais de interesse social é positiva, mas dentro da realidade da cidade essa concepção gera questionamentos entre os moradores que desejam sair e os que preferem ficar. Os habitantes das áreas úmidas estabelecem vínculos com o local de moradia, com a vizinhança, com o cenário, com os equipamentos existentes no bairro e até mesmo com as habitações, que podem ser concebidas de acordo com sua necessidade e condição econômica, e também pelo valor simbólico que possuem, pois o morador se apropria do espaço da moradia. Os vínculos criados com o local de moradia dificultam o processo de aceitação e transição para os conjuntos habitacionais e esse processo se agrava ainda mais quando a instalação do conjunto ocorre nas extremidades da cidade, seja na zona sul ou norte, pois são locais que ainda não possuem acesso eficiente ao transporte urbano, ao comércio e aos serviços básicos. 
$\mathrm{Na}$ cidade já existem mais de 4 grandes conjuntos habitacionais financiados pelo programa e nestes uma parcela das habitações é financiada pela Caixa Econômica e a outra é subsidiada pelo Governo. Apesar da tendência de crescimento desses residenciais, outra possibilidade a ser avaliada seria a implantação destes em áreas alagadas no perímetro urbano, o que diminuiria os custos, já que o material empregado seria a madeira e as estruturas básicas poderiam ser elaboradas pela mão-de-obra dos moradores, e assim ainda evitaria a perda da identidade cultural produzida nesses locais que retratam o modo de vida ribeirinho.

Atualmente o M inha Casa Minha Vida vem sendo atualizado e tem buscado novas opções para atender as demandas reais de cada local, tanto que desde 2013 o programa já permite a construção de imóveis em madeira, o que se concretizou inclusive na elaboração de um residencial com habitações feitas em madeira nas cidades de Curitiba e Pelotas. 0 programa apresenta propostas projetuais de baixo custo e adequadas as necessidades básicas, o que aponta para os indícios de que pode ser empregado como base projetual e remodelado para a realidade das áreas de ressaca em Macapá.

\section{REFERÊNCIAS PARA O ESTUDO}

Para o desenvolvimento e embasamento do estudo foram adotados exemplos que comprovassem a viabilidade da ocupação habitacional sobre as águas, o uso de novas tecnologias na construção de habitações populares e a aplicação de propostas arquitetônicas inovadoras. No processo de seleção das referências foram consideradas a temática do projeto e a área de implantação. As conclusões obtidas através da análise dessas referências serão empregadas na elaboração do programa de necessidades da habitação para as áreas alagadas.

A primeira referência utilizada foi a cidade de Afuá, localizada ao norte da Ilha de Marajó, no estado do Pará, com população estimada de 37.398 mil habitantes (IBGE, 2015), possui clima equatorial quente e úmido, com altas taxas de pluviometria e umidade. Uma das particularidades da cidade é a forma como foi construída, por se tratar de uma ilha todas as habitações existentes hoje no perímetro urbano são em madeira e dispostas sobre palafitas.

Em Afuá as habitações e as vias normalmente são concebidas de maneira espontânea pela própria população local, que emprega como principal material a madeira. As residências e edificações da cidade possuem entre 1 e 3 pavimentos, são construídas com tábuas de madeira, que após a construção é envernizada ou pintada com tinta para proteção e ornamentação da moradia.

No aspecto urbanístico e sanitário da cidade uma das grandes problemáticas é o saneamento básico, pois na cidade não existe um sistema adequado para tratamento ou armazenamento do esgoto e isso resulta no despejo dos dejetos diretamente nas águas dos rios, e estes são consequentemente levados pelo fluxo das águas, apesar 
de tratados de forma natural o despejo constante pode impulsionar impactos no ambiente aquático. 0 exemplo de Afuá, ilustrado na figura 2, enfatiza a possibilidade de uma grande estrutura urbana sobre as águas, mas ressalta que para isso é necessário planejamento urbanístico e sanitário adequado.

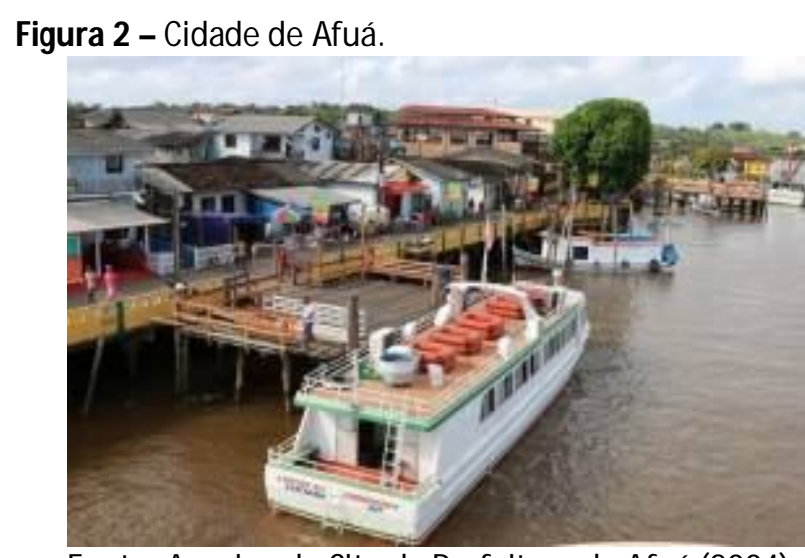

Fonte: Arquivo do Site da Prefeitura de Afuá (2004).

O segundo exemplo adotado como referência são as residências em madeira do programa Minha Casa Minha Vida. Até 2013 o programa não aceitava a construção de habitações feitas em madeira. A nova possibilidade trouxe consigo a redução nos custos, a agilidade no processo construtivo e ainda pode evitar a descaracterização da moradia em algumas regiões. 0 primeiro residencial com habitações em madeira feito com o auxílio do programa está localizado em Pelotas, Rio Grande do Sul, no Residencial Haragano, essa iniciativa foi desenvolvida em 2013, com 208 unidades residenciais e a tecnologia empregada na construção foi o Wood frame.

A tecnologia Wood frame propõe a aplicação de chapas de madeira reflorestada fixadas sobre uma trama de madeiras, se destaca por dinamizar o processo de construção, por reduzir consequentemente os custos da obra e os impactos causados no meio ambiente. A adoção da madeira como material para construção de residências através do Programa M inha Casa M inha Vida é um avanço nos critérios de qualidade, custo e possibilidade, pois proporciona a escolha do material que será empregado, uma redução no custo de produção das habitações e viabiliza a construção de residências em áreas com tipologias diferentes.

0 terceiro exemplo empregado no estudo foi o projeto conhecido como "Escola Flutuante de Makoko", foi projetado pelo arquiteto nigeriano Kunlé Adeyemi sobre a ótica de diretrizes ligadas a arquitetura, ao conforto ambiental e a sustentabilidade. A edificação é constituída de madeira e flutua através de barris para se adequar ao nível da água, comporta até 100 pessoas, possui forma triangular com disposição de grandes espaços vazados, altura de 10 metros do primeiro piso até o cume e se divide em três níveis: o nível térreo para área de lazer com jardim, o segundo para salas de aula e o terceiro para uma sala de aula com abertura e ventilada. 
Makoko está localizada na República Federativa da Nigéria, no estado de Lagos, uma região com população de 250 mil habitantes, instalada em área alagada e sujeita a aumentos frequentes do nível da água. Na região o acesso à saúde e educação é conflituoso, devido a economia do país e ao local onde a população está instalada, a área não apresenta condições adequadas para habitação e nem fornecimento dos serviços básicos, fatores que contribuem com o cenário de insalubridade e dificuldade vivenciado pela população local.

Foi pensando na situação vivenciada pelos moradores de Makoko, que 0 arquiteto e seu escritório de arquitetura NLÉ Architects desenvolveram esse projeto com apoio da ONU (Organização das Nações Unidas). 0 projeto foi posto em prática com o auxílio da própria comunidade, conforme figura 3, na construção foram empregados materiais locais, a concretização dessa ideia mostra na prática a viabilidade da concepção de um projeto inovador com materiais comuns e através de um processo que se assemelha ao da autoconstrução, pois a mão-de-obra empregada é a da própria população, o que dinamiza o processo e reduz custos.

Figura 3 - Protótipo da Escola de Makoko.

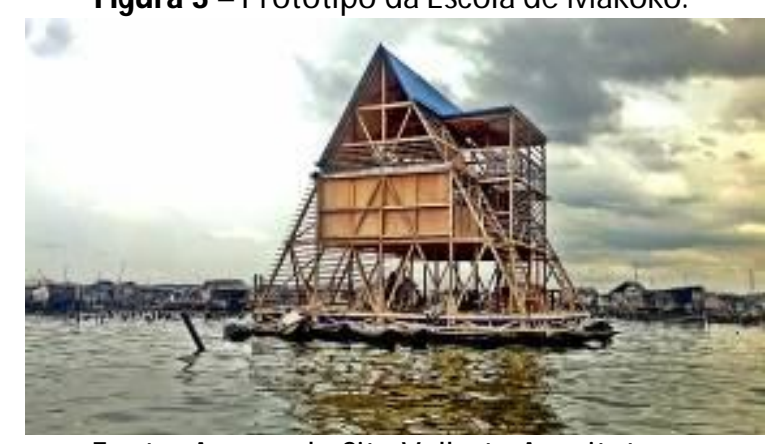

Fonte: Acervo do Site Vallarta Arquitetura.

A realidade analisada aponta que é possível pensar uma grande estrutura habitacional sobre as águas e que isso pode na realidade ser um atrativo que afirma as origens da cidade e atrai benefícios financeiros devido a atividades como o turismo. Os exemplos também deixam clara a necessidade de pensar na questão do saneamento existente, pois no caso da habitação sobre as águas esse critério pode se converter em um grande problema para os habitantes. A análise esclarece como as medidas tomadas para a concepção projetual devem considerar as necessidades populacionais, tendo em vista a ocupação habitacional e os serviços básicos que se ligam a ela. Das percepções mais notáveis observadas estão: o emprego da madeira como principal material para a construção, o uso de materiais disponíveis na região, e a aplicação da mão-de-obra dos habitantes locais como forma de dinamizar o processo de construção e consequentemente gerar a valorização do produto final que será produzido em parte pela própria clientela. 


\section{7 ÁREA DE ESTUDO E INTERVENÇÃO}

Após caracterizar a cidade e as ressacas é desenvolvida a apresentação da área de intervenção onde será implantado o conjunto habitacional Vila Ribeirinha. Para a elaboração do programa de necessidade é necessário ter conhecimento sobre as particularidades do local e da clientela do projeto. Nessa etapa foram utilizados questionários aplicados anteriormente no mesmo local. Os resultados obtidos auxiliaram no entendimento sobre as necessidades locais e a análise das habitações existentes.

A área de intervenção está localizada na Zona Sul da cidade de Macapá, no Bairro Jardim Marco Zero e é parte da Ressaca do Congós. Nas imagens que seguem na figura 4 estão dispostas da direita para esquerda respectivamente: a vista ampliada de parte do Bairro, com destaque para a localização da área de estudo no ponto vermeIho; a vista detalhada da parcela de área alagada que será utilizada como base para 0 projeto; e ainda a representação do traçado e das habitações existentes no local.

Figura 4 - Identificação geral e detalhada da área de intervenção.

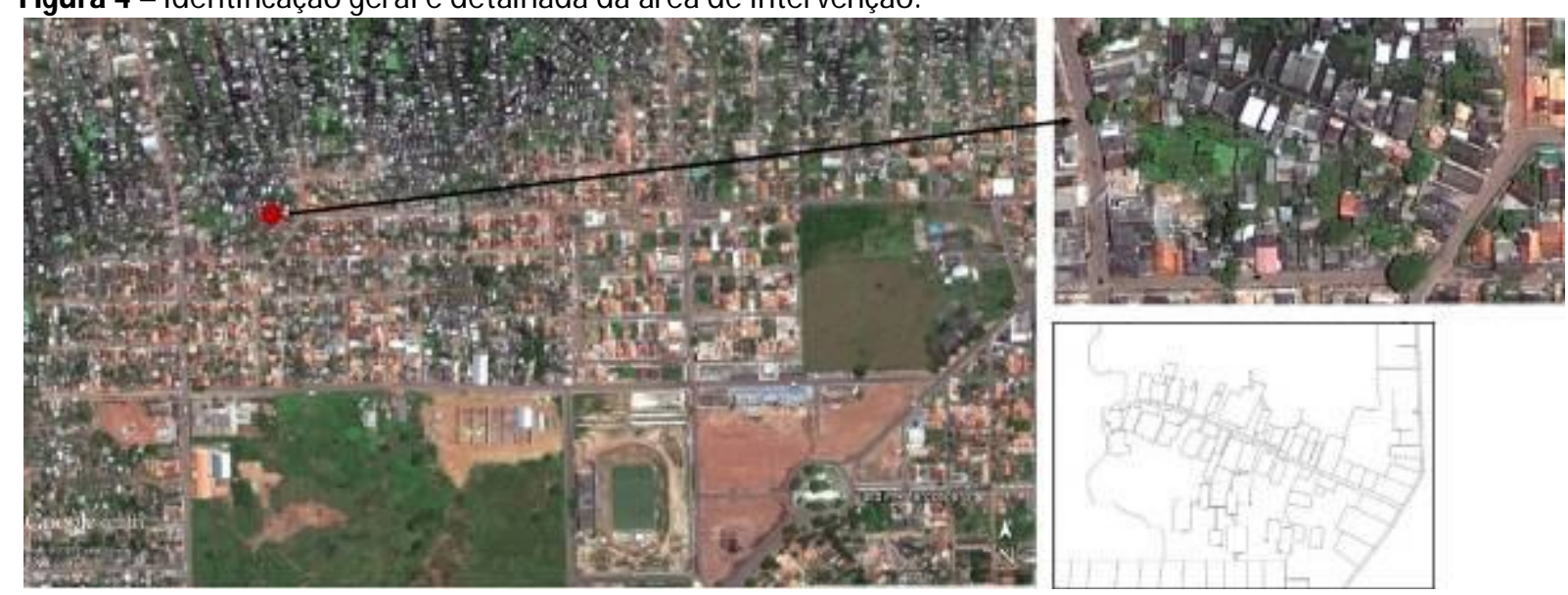

Fonte: adaptado de Google Earth.

0 ambiente de estudo está situado às margens da ressaca, com área total de $13.644 \mathrm{~m}^{2}$, por isso apresenta uma área de transição da terra firme para a área a alagada, atualmente o local comporta um total de 30 residências sobre as águas da ressaca e 14 em terra firme. Na figura 5 está disposta a delimitação da área de estudo e localização do projeto no bairro quanto as vias de acesso, as cores indicadas no mapa representam respectivamente: em azul claro a área alagada, em vermelho as habitações, em azul escuro as habitações de uso comercial e residencial, em marrom a área de terra firme, e em bege as vias de acesso ao conjunto. As vias que dão acesso a área são a Av. Júpiter, a Av. Netuno e a Rua da Estrela que compõe o fluxo do principal acesso ao local. 
Figura 5 - Mapeamento da área de intervenção.

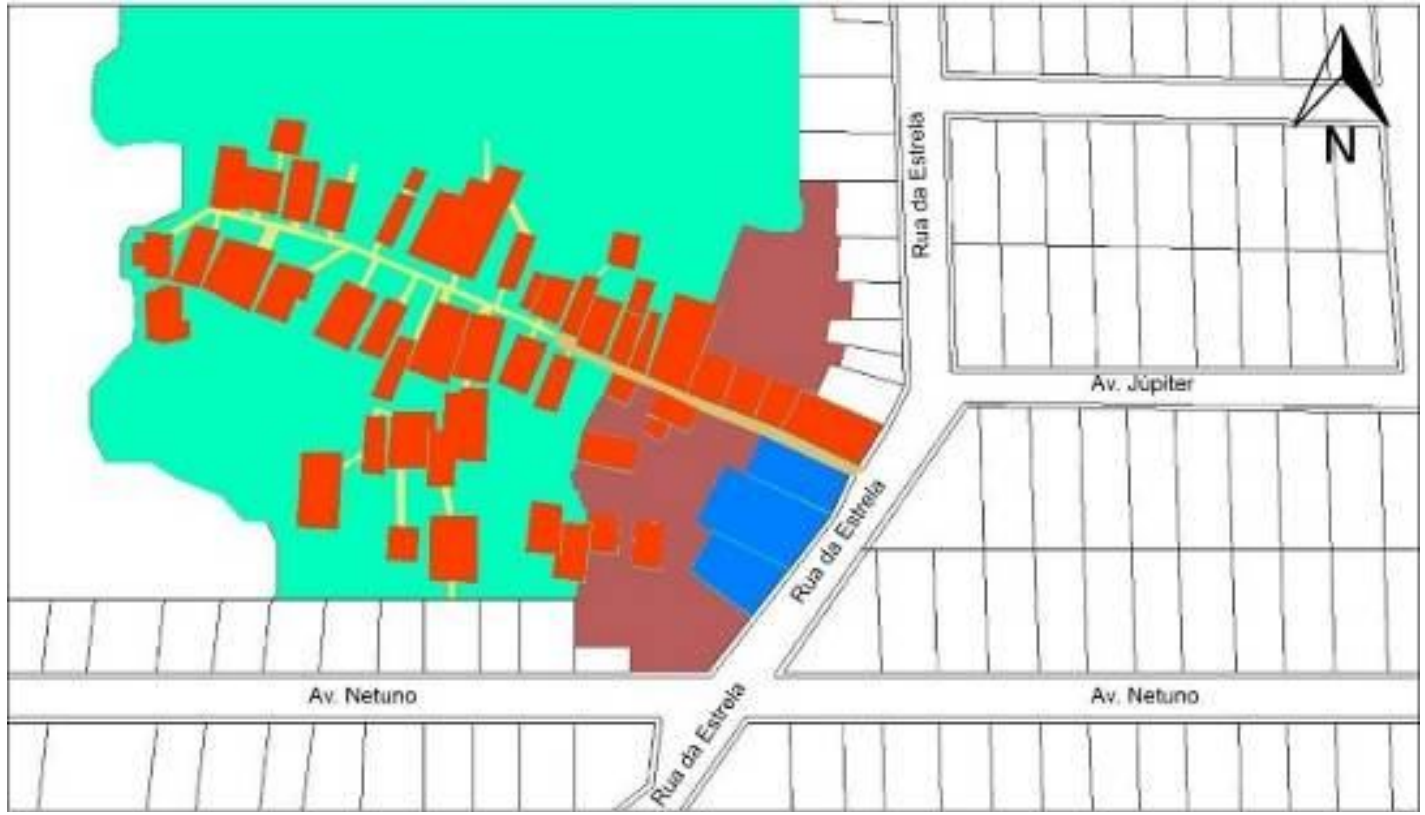

Fonte: acervo do autor.

$\mathrm{Na}$ área interna do conjunto se destacam as características típicas das áreas de ressaca ocupadas: presença constante da água sobre influência das chuvas e maré, presença de espécies aquáticas (vegetais e animais) e as habitações de madeira sobre palafitas. As habitações locais se conectam ao meio externo através das passarelas, que normalmente são feitas no mesmo nível da rua. A concepção dos acessos no mesmo nível da rua é um fator que limita as habitações a estarem mais próximas da água, nesse caso a ressaca possui a profundidade de 3,50 m, 0 nível da rua é de 5,00 $\mathrm{m}$ e 0 afastamento existente entre as residências e a água é de apenas 1,50 $\mathrm{m}$, conforme dados coletados no trabalho de campo.

\section{CARACTERIZAÇÃO DA CLIENTELA}

Para a elaboração de um projeto é fundamental conhecer a clientela e suas atividades. É necessário conhecer: o motivo da moradia na área, quais são as atividades exercidas pela população, quem são e que necessidades identificam.

Através da pesquisa feita na Ressaca no Congós foi possível identificar que a ocupação se deve principalmente à condição econômica das famílias e em segundo lugar a fatores como: a proximidade familiar, a localização próxima ao centro da cidade e a escolha própria. Do contingente total $60 \%$ é oriundo de llhas do Estado do Pará ou do Maranhão, pessoas que migraram para a cidade em busca de emprego e melhores condições de vida. As pessoas que vivem hoje na área aceitam a realidade de viver sobre as águas, não demonstram incômodos, muitas afirmam já estarem familiarizadas com o ambiente ribeirinho, pois parte delas já viveu em um ambiente semelhante ou sempre morou nas ressacas. 
Analisando a composição populacional do local é possível detectar a presença de todas as faixas etárias, com um destaque maior para a população de gênero feminino entre 20 e 30 anos de idade. A renda familiar média é de até um salário mínimo (R\$ $880,00)$ e normalmente é fruto da contribuição de até duas pessoas, sendo que a principal atividade exercida pelos habitantes é o trabalho informal, no caso masculino com serviços na área da construção e no caso feminino com serviços de limpeza. Por terem poucas condições financeiras os habitantes são inseridos cedo no cenário trabalhista e muitos dedicam quase todas as horas do dia em prol do trabalho, pois precisam do dinheiro para manter a família, e esse é um fator que dificulta a continuação ou conclusão dos estudos.

Mesmo não conhecendo a complexidade do ambiente e da infraestrutura básica de forma técnica, os habitantes conseguem detectar os principais problemas da área quando questionados. Dos problemas identificados por essa clientela estão: a coleta de lixo, o fornecimento de água e energia, a iluminação e os acessos, pois os habitantes classificam que estes itens não abrangem todo o perímetro da ressaca e não apresentam qualidade. Outra necessidade detectada através do diálogo obtido é a disponibilidade de ambientes coletivos para as funções de lazer e serviços, locais que pudessem abranger e viabilizar atividades dos moradores e também do governo para a comunidade.

\section{PROJETO VILA RIBEIRINHA}

Considerando a identificação das características da área física e das necessidades da clientela, a proposta da Vila parte da concepção de um conjunto habitacional com suporte para a vivência sobre as águas, onde se prevê: habitações corretamente distribuídas e ordenadas, o uso de materiais compatíveis com o meio ambiente, e áreas coletivas para o desenvolvimento de atividades de lazer, cultura e subsistência.

0 projeto contempla uma proposta de urbanização para a totalidade da área e projetos de arquitetura para as residências, vias de acesso e passarelas. Considerando como temática a ocupação nas áreas de ressaca, as diretrizes do projeto estão embasadas nos critérios de conforto ambiental, sustentabilidade e construção.

Com relação a temática de conforto foram avaliadas as recomendações de Barros (2001, p. 71) para a obtenção de conforto ambiental em habitações localizadas em zonas de clima quente e úmido. Para que seja possível obter uma zona de conforto adequada no projeto de urbanização e arquitetura serão adotadas as seguintes medidas: disposição de grandes esquadrias para o aproveitamento da ventilação; proteção das esquadrias contra a insolação direta, evitando a absorção de calor pelo ambiente; dimensionamento das paredes em uma espessura de até 10 centímetros, facilitando assim o processo de inércia térmica; aplicação de vegetação nas áreas de passeio e no entorno das edificações para produzir o sombreamento; disposição das ha- 
bitações permitindo a circulação da ventilação; aplicação de cores claras nas fachadas, para assim evitar que absorvam a radiação solar.

Quanto a temática de sustentabilidade, foi priorizado o aproveitamento dos materiais, o baixo impacto das obras no ambiente e a durabilidade das edificações produzidas. Diante dessa ótica e em acordo com as orientações de Zenid $(2009$, p.18) foram definidas as seguintes medidas para concretizar essas concepções: produção do projeto com as dimensões racionalizadas das peças de madeira empregadas para assim minimizar a perda com cortes e excessos do material; escolha correta da madeira para a construção do projeto, avaliando a durabilidade e origem; o tratamento da madeira empregada visando seu desempenho e durabilidade; reutilização das peças quando descartadas de uma função. Desse modo o material poderia atender outros usos e reduziria os custos. Ainda, quanto à questão da sustentabilidade foi pensada a coleta das águas servidas (esgoto sanitário) e depósito em local adequado, evitando assim o despejo direto nas áreas das ressacas.

No que corresponde ao quesito construtivo as diretrizes almejam o aproveitamento adequado dos materiais, a correta locação das edificações no terreno e o melhor aproveitamento do espaço. Dessa forma estão propostas as seguintes medidas: a correta implantação das habitações na área delimitada e em conformidade com os acessos disponíveis; a implantação das instalações de esgoto, energia e água abaixo das passarelas de acesso, evitando assim a poluição visual do ambiente, proporcionando mais espaço útil acima das passarelas e facilitando a manutenção; o direcionamento do esgoto coletado nas residências para uma estação de armazenamento em terra firme, sendo que está poderá ser esvaziada por veículo apto a dar o correto fim aos dejetos; a implantação de passarelas principais e secundárias com dimensões generosas e disposição de corrimãos, possibilitando o trânsito de pedestres e bicicletas; a implantação de postes de iluminação ao longo das passarelas; a disposição de um bicicletário em terra firme; e o aproveitamento da mão-de-obra local para induzir a participação e valorização do trabalho produzido.

\section{PROGRAMA DE NECESSIDADES}

O programa de necessidades ou programa arquitetônico consiste na listagem dos cômodos e elementos previstos para o projeto, juntamente com as funções e atividades correspondentes a esses espaços. Considerando as necessidades identificadas localmente, no projeto de urbanização do Conjunto Vila Ribeirinha foram dispostos ambientes para contemplar as atividades de lazer, interação social, saúde, moradia e mobilidade. No projeto arquitetônico, por se tratar de um conjunto habitacional, serão desenvolvidos os projetos arquitetônicos das habitações, passarelas e pontos comuns de convívio.

Os ambientes contemplados no conjunto serão: 
1. Habitações de pavimento térreo: ambientes dedicados a moradia, descanso, abrigo, permanência e alimentação.

2. Habitações de pavimento duplo: ambientes dedicados a moradia, descanso, abrigo, permanência e alimentação.

3. Praça: ambiente aberto dedicado a interação social, ações culturais e atividades comunitárias.

4. Creche: ambiente dedicado ao cuidado com crianças nos períodos da manhã e tarde.

5. Unidade básica de saúde: ambiente dedicado ao atendimento médico, vacinação, cuidados odontológicos e medicação.

6. Horta comunitária: ambiente aberto voltado para a produção coletiva de plantas e hortaliças pela própria comunidade.

7. Salão comunitário: ambiente dedicado a produção de eventos, reuniões e exibição de conteúdo (vídeos e palestras).

8. Área comercial: ambiente dedicado a venda de alimentos, utilidades e serviços.

9. Passarela principal: ambiente dedicado a fornecer acesso ao conjunto habitacional e entre suas áreas de uso comum.

10. Passarelas secundárias: ambiente dedicado a fornecer acesso direto as residências do conjunto habitacional

11. Pontos de convivência: ambiente localizado ao longo das passarelas e dedicados a interação social e lazer.

12. Deck: ambiente dedicado a contemplação da área, interação social e lazer.

13. Salão de artes: ambiente dedicado a manifestação de expressões artísticas, ao ensinamento de diversas artes e produção de oficinas.

As habitações serão de até 2 pavimentos e dotadas de: varanda, sala de estar/jantar, cozinha, área de serviço, banheiro, lavabo e até 3 dormitórios. 0 principal material empregado será a madeira, utilizada na estrutura e piso das habitações, aliado a ela estará o sistema construtivo Wood frame utilizado nas paredes. Na cobertura será aplicada a telha termo acústica, visto que seu desempenho térmico auxilia na redução do calor nos ambientes e o peso não afeta a estrutura da edificação. A aplicação destes materiais visa a obtenção de uma estrutura leve, ventilada e eficiente quanto ao conforto ambiental, estando em acordo com o requerido para a região norte. Quanto a parte externa a ideia é conservar a estética original das habitações, mantendo assim a disposição de tábuas horizontais na fachada, aliada a está concepção estará o emprego de esquadrias em madeira e vidro, o uso de guarda-corpo para proteção da circulação na varanda e a aplicação de tintas não tóxicas nos elementos de destaque externo, para que assim o resultado final seja leve e harmônico, conforme ilustrado na figura 6. 
Figura 6 - Perspectiva do projeto habitacional.
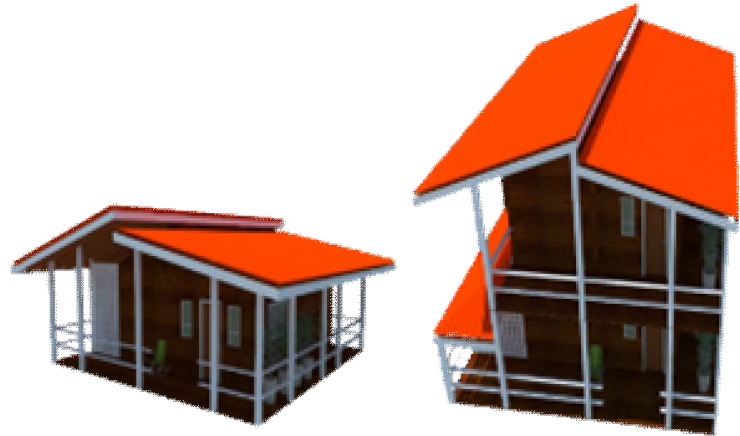

Fonte: acervo do autor.

As passarelas, conforme figura 7 , serão responsáveis pela conexão do conjunto habitacional com o meio externo e áreas internas, estas serão em madeira, dotadas de amplo espaço para a circulação e de guarda-corpos para segurança/suporte. Abaixo delas serão distribuídos os sistemas de abastecimento (de energia elétrica, telefonia e água) e a coleta de esgoto, proporcionando assim um ambiente de circulação menos conturbado e facilitando a manutenção dos sistemas por estarem condicionados em apenas um local. As passarelas se dividem em: principal, responsável pela conexão entre água e terra firme e dotada de 4 metros de largura; e secundárias, que farão a distribuição da circulação para as habitações e já serão dotadas de 2 metros de largura.

Figura 7 - Perspectiva e vista do projeto das passarelas. Fonte: acervo do autor.
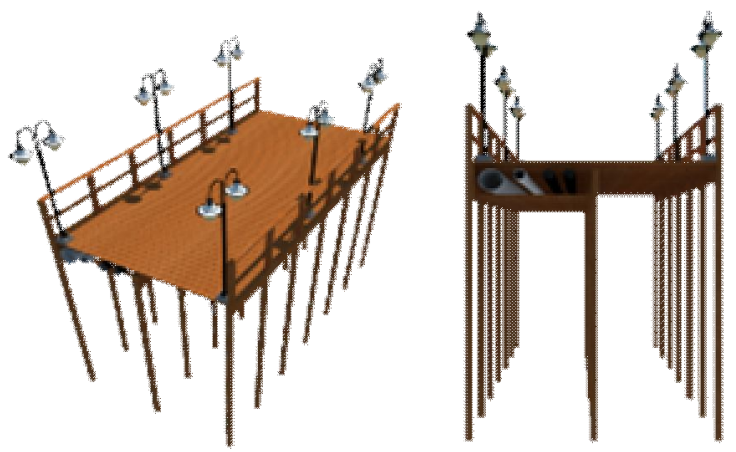

\section{RESULTADOS}

Atualmente a ocupação habitacional nas áreas de ressaca ainda é estigmatizada, vista como proposital e que possui como único objetivo a degradação do meio ambiente, pensamento comum onde não são considerados os fatores que induzem esse processo e a situação da população que se apropria dessas áreas. Ao caracterizar a cidade e o processo de ocupação das ressacas automaticamente são quebrados esses estigmas fixados pela sociedade, é possível compreender que a ocupação das áreas de ressaca é induzida e não constitui um problema recente, já que as primeiras ocu- 
pações desse gênero ocorreram há mais de 50 anos e que ao longo desse período 0 estado não se prontificou de controlar efetivamente essas ocupações.

A pesquisa desenvolvida na área revela através de seus dados que mais $80 \%$ das famílias que habitam as ressacas não possuem renda mensal suficiente para obter um lote em terra firme, o que ocorre principalmente devido a especulação imobiliária que toma a cidade e suas áreas centrais. Essas famílias conseguem arduamente a renda para a manutenção mensal familiar, a redução em custos como o transporte, 0 acesso ao ensino e a educação acabam sendo preteridos em detrimento da escolha do lugar de moradia, principalmente porque os sistemas que abastecem a cidade já apresentam falhas na área central, e a medida que se afasta dessa a qualidade é reduzida consequentemente.

A facilidade na aceitação da ressaca como ambiente de moradia se deve principalmente ao entendimento de que a área alagada não se distancia da área de terra firme, nesse processo os moradores revogam os riscos de habitarem esses locais pois esta é a única alternativa viável na condição em que se encontram. Quando questionados os habitantes afirmam inclusive a preferência pela área onde vivem em detrimento dos conjuntos habitacionais feitos pelo governo, pois estes são implantados longe do centro da cidade e quebram a configuração de moradia que existia antes nas ressacas, já que se tratam de prédios com apartamentos menores que não preservam a vizinhança anterior e nem possibilitam a singularidade de cada residência. Nessa situação o que se detecta é o apego desses moradores com o local, a ressaca assume o papel de "lar" e os problemas detectados por eles não são atribuídos ao ambiente, mas sim a falta de planejamento e o mal atendimento dos serviços básicos como água, energia e iluminação.

A própria legislação e a postura governamental deixam a desejar no critério de proteção dessas áreas, a legislação apenas estabelece que esses locais devem ser conservados, não é vetada diretamente a ocupação e sim a degradação ou descaracterização do ambiente. A ocupação hoje só gera danos devido a falta de planejamento e de adoção de medidas que reduzam os impactos da moradia enquanto não são tomadas decisões definitivas pelos entes responsáveis.

Atualmente um grande percentual das ressacas existentes na cidade de Macapá estão ocupadas. São residências e famílias que não possuem outro lugar para morar. M over esse contingente para habitações populares demandaria um custo muito alto, e é diante dessa situação e dos fatores já elencados que a proposta da Vila Ribeirinha se aplica como uma alternativa viável, de menor custo e execução mais rápida quando comparado ao método tradicional.

A proposta de produção de conjuntos habitacionais nas áreas onde a ocupação já existe iria propiciar uma solução para a condição e qualidade de vida dos habitantes e ainda seria capaz de frear a degradação desse ambiente, produziria um cenário que representa a origem da vivência amapaense e a convivência harmoniosa com esse 
ecossistema. Uma proposta que atende as necessidades dos habitantes locais e que se adéqua a realidade colocada pela legislação.

\section{BIBLIOGRAFIA}

ÁLVARES, Ana María; BAHAMÓN, Alejandro. Palafito: de arquitectura vernácula a contemporânea. Paramón Ediciones, Barcelona, 2009.

BARROS, Anésia Barros Frota; SCHIFFER, Sueli Ramos. Manual de Conforto Térmico. São Paulo: Studio Nobel, 2001.

NERI, Sara Heloiza Alberto. A utilização das ferramentas de geoprocessamento para identificação de comunidades expostas a hepatite a nas áreas de ressacas dos municípios de Macapá e Santana/ AP. Rio de Janeiro: UFRJ, 2004. 189 f. Tese (M estrado em Engenharia) - Programa de Pós-graduação em Engenharia, Universidade Federal do Rio de Janeiro, Rio de Janeiro, 2004.

PORTILHO, Ivone. Áreas de Ressaca e Dinâmica Urbana em Macapá/AP. Trabalho apresentado no VI Seminário Latino-americano de Geografia Física, Coimbra, 2010.

SALES, Josicléia da Silva; SANTOS, M arcelo M oreira dos. Proteção jurídica das Áreas de Ressaca em Macapá. Trabalho apresentado no Seminário Nacional sobre Áreas de Preservação Permanente em M eio urbano, Natal, 2012.

ZENID, Geraldo José. Madeira: uso sustentável na construção civil. São Paulo: Instituto de Pesquisas Tecnológica: SVM A, 2009.

Artigo recebido em 14 de julho de 2016.

Aprovado em 18 de julho de 2016. 